\title{
Antidiabetic Activity of Sida Rhombifolia (L) leaf extract
}

\author{
Lekshmi Gangadhar, Anooj E.S, M.Charumathy, Vibala. B.V
}

\begin{abstract}
Diabetes mellitus is a metabolic disease that is a major health problem today, the prevalence of which in latest years has been rapidly increasing worldwide. It was also considered as an untreatable metabolic illness that affects about $2.8 \%$ of the inhabitants of the world. This study was aim to analyses the quantitative and qualitative phytochemistry and antidiabetic activity of Sida rhombifolia leaf extract. Maximum scavenging activity of alpha amylase inhibition assay of different extract was observed that the ethanol exhibited comparable to the another concentration activity in the maximum activity to compare with another value in the inhibition. Glucose uptake by yeast activity of different extract was observed the ethyl acetate exhibited comparable are responsible to maximum percentage protection. Result indicated that the sida rhombifolia $(L$.$) plant$ ethyl acetate extract shows $82.30 \%$ of activity was recorded the Sida rhombifolia $(L$.) leaf extract cum. The overall results have clearly indicated that the extract could be used as a therapeutic agent. Though further analysis is needed as clinical trials and other advanced approaches to confirm this as a safer therapeutic medicine.
\end{abstract}

Keywords : Antidiabetic, Alpha amylase, inhibition assay, Glucose, Phytochemical analysis

\section{INTRODUCTION}

Diabetes mellitus (DM) is a chronic disorder associated by insulin production defect and or both of its intervention. In many other metabolism within the human body, this contributes to extended hyperglycemia with alterations [1]. Diabetes has an implicit relationship with the most prevalent endocrine disorder in many other illnesses. Approximately 200 million individuals globally were projected to have benefited from DM in 2010, and by 2025 it is anticipated to achieve 300 million [2]. Depending on the disease etiology, diabetes mellitus is categorized into distinct categories, but the two main kinds are commonly adopted: type 1 (IDDM) and type 2 (NIDDM) [3]. In addition, there is also another short-term diabetes-related disease recognized as mellitus gestational diabetes (GD). It relates to the incidence of glucose intolerance or initial identification throughout the pregnancy era. Other diseases involve genetic pancreatic

Revised Version Manuscript Received on September 16, 2019.

Lekshmi Gangadhar, Xcellogen Biotech INDIA Pvt Ltd, Nagercoil, Tamilnadu, India

(Email: xcellogenbiotech@gmail.com) India

(Email: xcellogenbiotech@gmail.com)

Dr.M.Charumathy, Assistant Professor, Department of Biochemistry,

Marudhar Kesari Jain College For Women, Vaniyambadi -635751,

Tamilnadu, India.

(Email: sarumathym09@gmail.com)

Vibala. B.V, Xcellogen Biotech INDIA Pvt Ltd, Nagercoil, Tamilnadu, India

(Email: xcellogenbiotech@gmail.com)
Anooj E.S, Xcellogen Biotech INDIA Pvt Ltd, Nagercoil, Tamilnadu,

B-cell disorders or mutations of insulin receptors or deformities of post-receptors [3].

Fasting plasma glucose (FPG) concentration assessment, which takes place early in the morning, is the most common diabetes diagnostic methods. It is regarded normal for patients with FPG below $100 \mathrm{mg} / \mathrm{dl}$; those between 100 and $125 \mathrm{mg} / \mathrm{dl}$ are pre-diabetes while those above $125 \mathrm{mg} / \mathrm{dl}$ are diabetic[4]. The current oral antidiabetics involve sulfhonyl ureas that reduce blood sugar, primarily by increasing insulin production from Langerhans islets. They are coupled with receptors of sulfonyl urea on $B$ cells leading to the closure of adenosine triphosphate-dependent potassium channels. As a result, depolarization of the cell membrane and the subsequent influx of calcium accompanied by secretion of stored insulin from secretory granules occurs within the cells. This process only performs when insulin is present [4 ]. The "starch blockers" alpha-glucosidase inhibitors block certain enzymes that cause carbohydrate decomposition in the small intestine. They function primarily by reducing the absorption level of carbohydrate in the body $[5,6]$. In addition, by adding to the carbohydrate-binding region and interacting with their hydrolysis in mono-saccharides, acarbose reversibly inhibits both pancreatic alpha-amylase and ß-glucosidase enzymes[7 ]. This findings in slower absorption and reduced levels of postprandial blood sugar.In order to eliminate these side effects, it is better to in troduce hypoglycemic herbs so that they can be used in conj unction with standard drugs.

\section{MATERIALS AND METHODS}

\section{Collection of sample:}

The flowering plant of Sida rhombifolia leaves were collected from road sides and around the Vellore district, Tamil nadu during December, 2018 .The sample was authenfied from botanical survey of India. The leaves were gently washed with tap water, then rinsed with distilled water. Then air dried and powered to mesh and preparation.

\section{Sequential extraction:}

Sida rhombifolia leaves about $(100 \mathrm{gm})$ of dried powder was placed in $300 \mathrm{ml}$ of hexane for added 24 hours .After 24 hours mixed and then filtered by using whatmann's filter paper. The filtered thus obtained was cool and concentrated to dryness. Then dry leaf powder $(100 \mathrm{gm})$ was placed in $300 \mathrm{ml}$ of ethyl acetate for added 24 hours in maceration. After 24 hours mixed and then filtered thus obtained was 
cooled and concentrated to dryness. Then dry powder of leaves in $(100 \mathrm{gm})$ was placed $300 \mathrm{ml}$ of ethanol for 24 hours maceration. After 24 hours mixed and filtered thus obtained to cool. Then the extraction mixture was filtered and red concentrated of distilling unit. Then its residues were weighed and kept in bottle to use phytochemical and other biological screening methods. Then collected filtrate.

\section{Alpha-Amylase Inhibition Assay:}

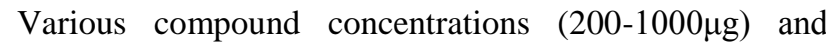
incubate $500 \mu \mathrm{l}$ of $0.02 \mathrm{~mol} / 1$ sodium phosphate buffer $(\mathrm{pH}$ 6.9 with $0.006 \mathrm{~m} \mathrm{~mol} / 1 \mathrm{Nacl}$ ) with porcine pancreatic alpha amylase enzyme $(0.5 \mathrm{mg} / \mathrm{ml})$ at $25^{\circ} \mathrm{c}$ for $10 \mathrm{minT}$ The reaction mixture was introduced after the $500 \mu$ l of $1 \%$ starch solution in $0.02 \mathrm{~mol} / 1$ of sodium phosphate buffer $(\mathrm{pH} 6.9$ with $0.006 \mathrm{~mol} / 1 \mathrm{Nacl})$. The reaction mixture was then incubated for $10 \mathrm{~min}$ at $25^{\circ} \mathrm{cThe}$ procedure was lastly halted by incubation in the boiling water bath $(5 \mathrm{~min})$ and cooled to room temperature, followed by the addition of $1.0 \mathrm{ml}$ of Dinitrosalicylic acid (DNS). With $10 \mathrm{ml}$ of distilled water, the reaction mixture was diluted. The colorimetric absorption measure at $540 \mathrm{~nm}$. The reaction mixture of all reagents and enzymes with the exception of the test sample was used as control. The inhibition percentage was shown as an outcome of alpha amylase inhibitor activity. The inhibition percentage was calculated using the given formula,

$\%$ Inhibition $=($ Abs Control - Abs Sample $) /$ Abs Control $* \mathbf{1 0 0}$

\section{Yeast Cell Glucose Uptake:}

The yeast cell was formed by Cirillo et al (1962) technique. Saccharomyces cerevisiae was suspended distilled water and was washed by repeated centrifugation (4200rpm, $5 \mathrm{~min}$ ) in distilled water until pellet appeared clear. A $5 \%$ ( w/w) suspension of washed yeast was prepared in distilled water.

The yeast cell's glucose uptake was evaluated. Four concentrations of this compound $(25,50,75,100 \mu \mathrm{g} / \mathrm{ml})$ were prepared. A standard glucose concentration of $100 \mathrm{mM} / \mathrm{L}$ was prepared. Different extract concentrations were introduced to the $1 \mathrm{ml}$ of glucose solution and incubated at $37 \mathrm{oc}$ for 10 minitues. The reaction was initiated with $100 \mu \mathrm{l}$ of vortexed yeast suspension and further incubated at $37 \mathrm{oc}$ for 60 minutes. After incubation the tubes were centrifuged (3800rpm, 5min) and Glucose was measured using anthrone technique in the supernatant.

Increase in glucose uptake $(\%)=(\mathrm{Abs}$ control-Abs sample) / Abs control $* \mathbf{1 0 0}$

Where, Abs control is the control reaction absorbance (which contains all reagents except the sample) and Abs sample is the test sample absorbance

\section{RESULTS AND DISCUSSION}

Alpha-Amylase Inhibition Assay Sida Rhombifolia (L.)

$\alpha$ - Amylase inhibition assay scavenging activity in hexane, ethyl acetate and ethanol extract Sidarhombifolia $(L)$
Table 1: The inhibition percentage of Hexane

\begin{tabular}{|l|l|l|}
\hline $\begin{array}{l}\text { Concentration in } \\
\mu \mathrm{g}\end{array}$ & $\begin{array}{l}\text { \%Inhibition(C-S) } \\
/ \mathrm{Cx} 100\end{array}$ & $\begin{array}{l}\text { \% Inhibition(C-S) } \\
/ \mathrm{Cx} 100\end{array}$ \\
\hline 200 & $68.63 \%$ & $89.28 \%$ \\
\hline 400 & $59.06 \%$ & $89.92 \%$ \\
\hline 600 & $46.05 \%$ & $93.36 \%$ \\
\hline 800 & $31.65 \%$ & $94.38 \%$ \\
\hline 1000 & $18.26 \%$ & $95.66 \%$ \\
\hline
\end{tabular}

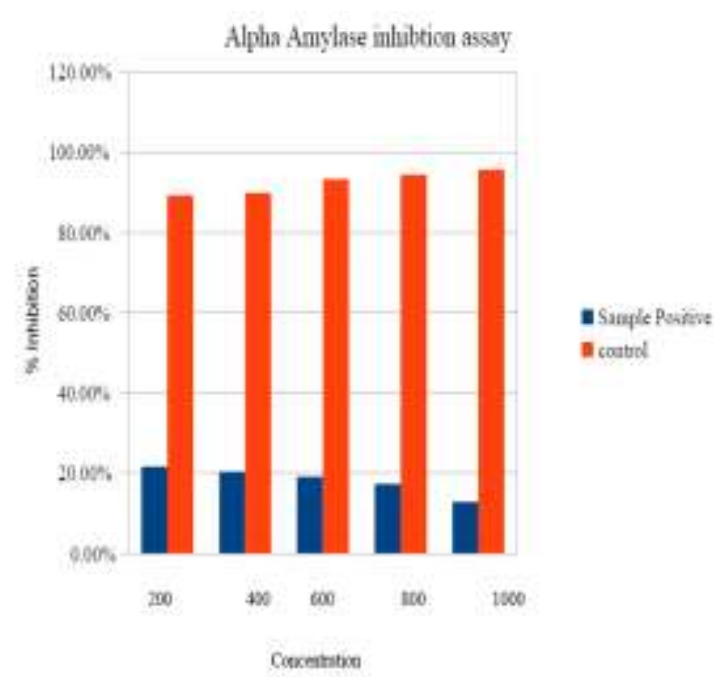

Figure 1: Alpha amylase inhibition scavenging activity was observed in hexane extract of Sida rhombifolia $(L$. $)$

Table.2:The inhibition percentage of Ethyl Acetate

\begin{tabular}{|l|l|l|}
\hline $\begin{array}{l}\text { Concentration in } \\
\mu \mathrm{g}\end{array}$ & $\begin{array}{l}\text { \%Inhibition(C-S) } \\
/ \mathrm{Cx} 100\end{array}$ & $\begin{array}{l}\text { \%Inhibition(C-P. } \\
\mathrm{C}) / \mathrm{C} \times 100\end{array}$ \\
\hline 200 & $20.35 \%$ & $89.28 \%$ \\
\hline 400 & $19.26 \%$ & $89.92 \%$ \\
\hline 600 & $16.78 \%$ & $93.36 \%$ \\
\hline 800 & $14.43 \%$ & $94.38 \%$ \\
\hline 1000 & $13.01 \%$ & $95.66 \%$ \\
\hline
\end{tabular}

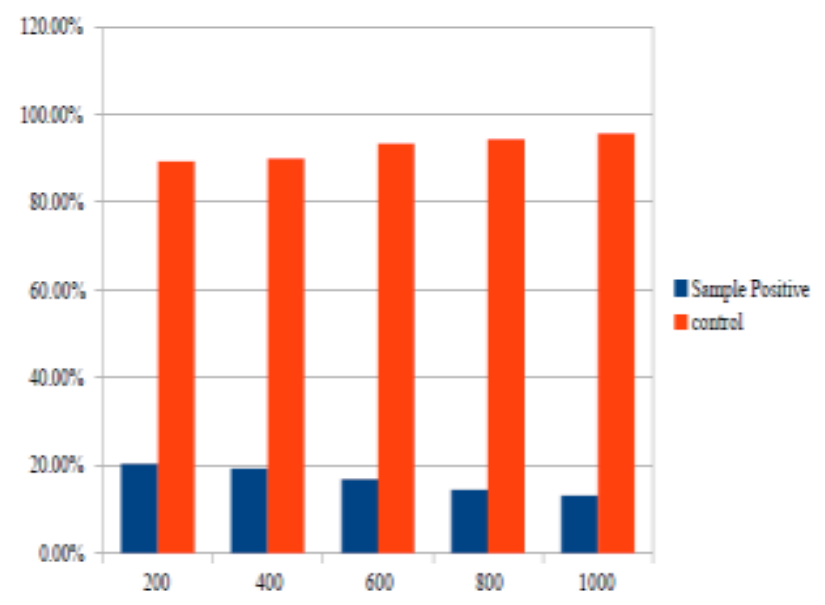

Figure 2: Alpha amylase inhibition scavenging activity was observed in ethyl acetate extract of Sida rhombifolia(L.) 
Table.3:The Inhibition Percentage of Ethanol

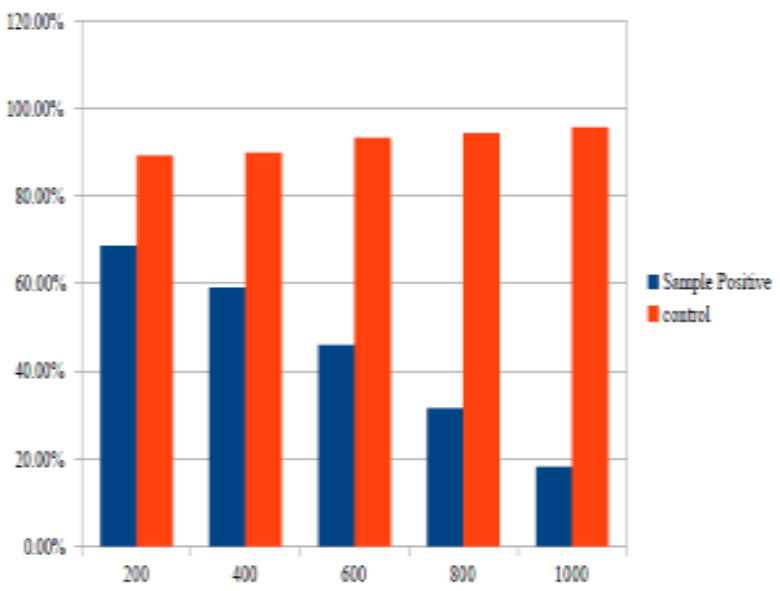

Figure 3: Alpha amylase inhibition scavenging activity was observed in ethanolic extract of Sida rhombifolia $(L$. $)$

The results are summarized Table1, Table2, Table3. It was observed that the water and ethanol soluble of content as selected leaf extract $(10 \mathrm{mg} / \mathrm{ml})$ were found be potent $\alpha$-amylase inhibition assay agents. The maximum scavenging activity was observed in ethanolic extract of Sida rhombifolia(L.)retusa $(68.63 \%)$ while maximum activity of compare with another value of inhibition.

Yeast glucose uptake:

The antidiabetic activity of the drug should be evaluated with glucose uptake by yeast. Then the percentage will be increased in glucose concentration.

$\alpha$ - The glucose uptake by the yeast in hexane, ethyl acetate and ethanol extract of Sidarhombifolia $(L)$

Table.4: The Increase In Glucose Uptake (\%) of Hexane

\begin{tabular}{|l|l|l|}
\hline \multicolumn{3}{|l|}{ Mean \% Inhibition } \\
\hline $\begin{array}{l}\text { Concentration } \\
\text { in } \mu \mathrm{g}\end{array}$ & Compound\% & Acarbose\% \\
\hline 25 & $73.32 \%$ & $43.45 \%$ \\
\hline 50 & $62.94 \%$ & $31.03 \%$ \\
\hline 75 & $54.89 \%$ & $25.36 \%$ \\
\hline 100 & $45.73 \%$ & 14.93 \\
\hline
\end{tabular}

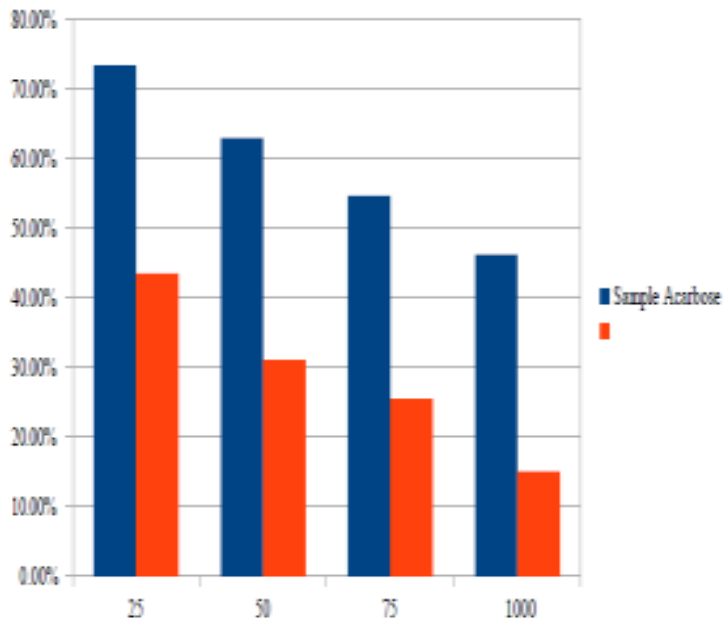

Figure 4: The Glucose uptake by yeast in hexane extract of Sidarhombifolia $(L)$
Table.5: The Increase In Glucose Uptake (\%) Ethyl Acetate:

\begin{tabular}{|l|l|l|}
\hline \multicolumn{3}{|l|}{ Mean \% Inhibition } \\
\hline $\begin{array}{l}\text { Concentration } \\
\text { in } \mu \mathrm{g}\end{array}$ & \%Compound & \%Acarbose \\
\hline 25 & $82.30 \%$ & $43.45 \%$ \\
\hline 50 & $73.70 \%$ & $31.03 \%$ \\
\hline 75 & $64.42 \%$ & $25.36 \%$ \\
\hline 100 & $55.83 \%$ & $14.93 \%$ \\
\hline
\end{tabular}

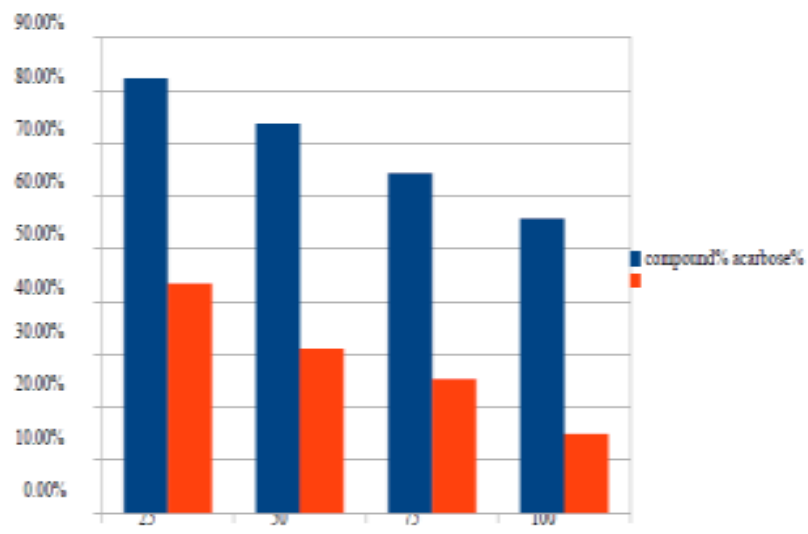

Figure 5: The Glucose uptake by yeast in ethyl acetate extract of Sidarhombifolia $(L)$

Table.6: The Increase In Glucose Uptake (\%) Ethanol:

\begin{tabular}{|l|l|l|}
\hline \multicolumn{3}{|l|}{ \%ean inihibition } \\
\hline $\begin{array}{l}\text { Concentration in } \\
\mu \mathrm{g}\end{array}$ & \%Compound & \%carbose \\
\hline 25 & $72.18 \%$ & $43.45 \%$ \\
\hline 50 & $65.35 \%$ & $31.03 \%$ \\
\hline 75 & $52.24 \%$ & $25.36 \%$ \\
\hline 100 & $46.63 \%$ & $14.93 \%$ \\
\hline
\end{tabular}

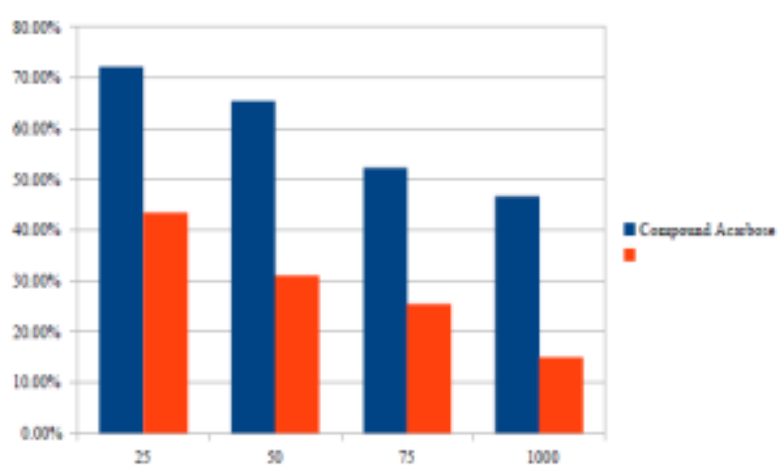

Figure 6: The Glucose uptake by yeast in ethanolic extract of Sidarhombifolia $(L)$

The glucose uptake by yeast activity of different extract was observed the ethyl acetate exhibited to comparable are responsible to maximum \% protection. Result indicated that the Sida rhombifolia(L.) leaves from ethyl acetate extract shows $82.30 \%$ of activity was recorded to comparable to another extract of cum through inhibition.

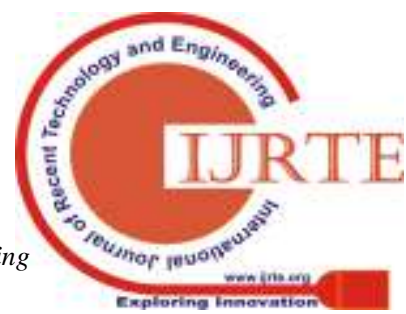




\section{CONCLUSION}

Diabetes mellitus is a terrible disease triggered by increas ed manufacturing of hepatic glucose and impaired action of $i$ nsulin. Over the past three centuries, the use of herbal medic ine has grown dramatically in both developing and develope $\mathrm{d}$ countries. The alpha amylase inhibition assay in showed that the extract was highly effective and the result of induced cum treated with comparable to the control activity inhibition. The effect of Sida rhombifolia extract on the other hand is comparable to treated with antidiabetic drug. This was confirmed by the glucose uptake by yeast analysis. The effect is attributed to the rich chemical composition of Sida rhombifolia extract such saponins, flavonoids, alkaloids, phenols etc. The overall results have clearly indicated that the extract could be used as therapeutic agent. Through further analysis is needed as clinical trials and other high tech approaches to confirm the same in order to confirm as safer therapeutic medicine in antidiabetic activity significant.

\section{REFERENCES}

1. Amos AF, McCarty DJ, Zimmet P (1997) The rising global burden of diabetes and its complications: estimates and projections to the year 2010. Diabetic medicine 14: S7-S85.

2. Atkinson MA, Maclaren NK (1994)The pathogenesis of insulin-dependent diabetes mellitus. New Eng J Med 331:1428-1436.

3. Akendegue B. (1992) Medicinal plants used by the Fang traditional healers in Equatorial Guinea.J Ethnopharmacol.; 37(2): 165-173.

4. Arseculeratne SN, Gunatilaka AAL, Panabokke RG. (1985) Studies on medicinal plants of Sri Lanka. Part 14: Toxicity of some traditional medicinal herbs, Journal of Ethnopharmacology; 13:323-335.

5. Bastaki A(2005) Diabetes mellitus and its treatment. Int J Diabetes metabolism 13: 111-134.

6. Bearse MA, Han Y, Schneck ME, Barez S, Jacobsen C, et al. (2004) Local multifocal oscillatory potential abnormalities in diabetes and early diabetic retinopathy. Inv ophthalmol visual sci 45: 3259-3265.

7. Betterle C, Zanette F, Pedini B, Presotto F, Rapp LB, et al. (1984) Clinical and subclinical organ-specific autoimmune manifestations in type 1 (insulin- dependent) diabetic patients and their first-degree relatives. Diabetologia 26: 431-436. 